Review Article

\title{
Magnetic Nanoparticles@Metal-Organic Framework Composites as Sustainable Environment Adsorbents
}

\author{
Gege Zhao, ${ }^{1}$ Nianqiao Qin, ${ }^{1}$ An Pan, ${ }^{1,2}$ Xiaoyan Wu, ${ }^{1}$ Chuanyi Peng, ${ }^{1,2}$ Fei Ke ${ }^{D},{ }^{1}$ \\ Mudassar Iqbal, ${ }^{3}$ Karna Ramachandraiah, ${ }^{4}$ and Jing Zhu $\mathbb{D}^{1}$ \\ ${ }^{1}$ Department of Applied Chemistry and State Key Laboratory of Tea Plant Biology and Utilization, Anhui Agricultural University, \\ Hefei 230036, China \\ ${ }^{2}$ School of Tea and Food Science \& Technology, Anhui Agricultural University, Hefei 230036, China \\ ${ }^{3}$ Department of Agricultural Chemistry, The University of Agriculture Peshawar, Pakistan \\ ${ }^{4}$ School of Life Sciences, Department of Food Science and Biotechnology, Sejong University, Seoul 05006, Republic of Korea
}

Correspondence should be addressed to Fei Ke; kefei@ahau.edu.cn and Jing Zhu; zhujing@ahau.edu.cn

Received 16 July 2019; Revised 31 August 2019; Accepted 18 September 2019; Published 27 October 2019

Academic Editor: Ilaria Fratoddi

Copyright (c) 2019 Gege Zhao et al. This is an open access article distributed under the Creative Commons Attribution License, which permits unrestricted use, distribution, and reproduction in any medium, provided the original work is properly cited.

\begin{abstract}
Metal-organic frameworks (MOFs) are an intriguing class of porous inorganic-organic hybrid networks synthesized from metal ions with multidentate organic ligands. MOFs have uniform and tunable cavities and tailorable chemistry, making them promising materials for hazardous component removal from the environment. Controllable integration of magnetic nanoparticles (NPs) and MOFs is leading to the creation of many novel multifunctional MOF-based composites, which exhibit advanced performance that is superior to both of the individual units. This review summarizes the recent significant advances in the development of MOF-based magnetic heterostructure materials for the removal of hazardous contaminants from the environment. The successful methods reported till date for the magnetic MOF synthesis are also provided. In the final section, we provide our views on the future development of the magnetic MOF heterostructure materials for the pollution management.
\end{abstract}

\section{Introduction}

In recent years, environmental pollution is increasing and posing serious threat to the ecosystem and human health [1]. Inorganic pollutants such as heavy metal ions in water have drawn much attention due to their long half-life and nonbiodegradability. For these reasons, numerous technologies have been developed for water purification, such as ion exchange [2], biological treatment [3], chemical precipitation [4], and reverse osmosis [5]. Although these technologies are effective, their practical applications are usually hampered by the high cost and poor selectivity. On the other hand, dyes are considered as serious organic pollutants, which are produced by various industrial wastewater such as textile, leather, printing, plastics, cosmetics, pharmaceutical, and food wastewater [6,7]. The presence of dyes not only gives rise to high visibility but also can reduce the solubility of gas in water and even more has a strong toxicity and carcino- genicity to the human body. Therefore, the removal of inorganic and organic pollutants from wastewater is very necessary for water safety and human health protection. Compared with these methods, adsorption is considered as an ideal pollution treatment method due to its low cost, strong universality, and simple operation [8]. Traditional adsorbents, such as zeolite, metal oxide, and activated carbon, cannot show satisfactory adsorption capacity or require long contact time $[9,10]$. Hence, the development of a novel high efficiency adsorbent with large capacity will be an important challenge.

Metal-organic frameworks (MOFs) are constructed by ditopic or polytopic organic ligands and transition metal ions or clusters [11]. Owning to their diverse structures, adjustable aperture, large surface area, and coordinated unsaturated metal sites, MOFs have been widely used in social and industrial fields, such as gas storage [12], separation [13], catalysis [14], sensing [15], and drug delivery [16]. In particular, 
adsorption is one of the most potential applications for MOFs during the past 20 years. Compared with traditional adsorbents, MOFs have huge porosity and tunable pore sizes, endowing highly selective adsorption of hazardous contaminants from the environment [17]. However, these novel MOF-based adsorbents are difficult to be recycled from the mixture solution. To overcome this problem, combining MOFs with magnetic nanoparticles (NPs) has been made due to their high adsorption capacity, easy functionality, and easy isolation with an external magnetic field. The methods of preparing magnetic MOF composites include the hydrothermal method [18] and layer-by-layer assembly method [19]. These composite materials have the magnetic response on the basis of magnetic particles, which facilitates product recovery and lower operational cost in MOF separation. Moreover, the components of MOF-based magnetic composites can be easily engineered [20-22]. Hence, compared to conventional adsorbents used in the environmental pollution treatment, the MOF-based magnetic adsorbents are more suitable for industrial applications. Although magnetic composites at the industrial scale are still facing great challenges, numerous magnetic particles are commercially available, making the magnetic MOFs compatible with commercial applications in the near future [23].

In this review, we summarize the recent significant progress in the development of MOF-based magnetic nanocomposites for hazardous contaminant removal from the environment (Figure 1). The structures, properties, and the methods for the synthesis of the magnetic nanocomposites are discussed briefly. Particular challenges of MOF-based magnetic NPs for further development toward adsorption applications are critically discussed.

\section{Design and Synthesis of Magnetic NP@MOF Structure}

Magnetic metal-organic framework nanocomposites are new functional materials that have emerged in recent years [24]. They are composed of porous MOFs and magnetic NPs. It not only retains the structure and performance of the MOF material but also increases the magnetic properties of the granular material. It can be separated and recovered from the mix aqueous solution or soil by using a magnet and has the advantages of high selectivity, good dispersion, and multiple reuse [25]. It can be recycled again and is in line with the green concept. The synthesis of magnetic NP@MOFs generally can be seen as the following four methods.

2.1. Presynthesized Magnetic NP Template Method. In this method, the presynthesized magnetic NPs are used as seeds to grow MOFs. Firstly, the presynthesized magnetic NPs should be functionalized by capping agents or surfactants. For instance, Li et al. reported MOF-5@SiO $\mathrm{SFe}_{3} \mathrm{O}_{4}$ coreshell magnetic catalysts, which were prepared through coating the typical MOF-5 on the surface of $\mathrm{SiO}_{2} @ \mathrm{Fe}_{3} \mathrm{O}_{4} \mathrm{NPs}$ [26]. The results displayed that the as-synthesized magnetic core-shell nanocomposites can be easily separated from the mixture reaction system by a magnet. Zhao et al. also reported the synthesis of magnetic $\mathrm{Fe}_{3} \mathrm{O}_{4} @ \mathrm{MOF}$ and demon-

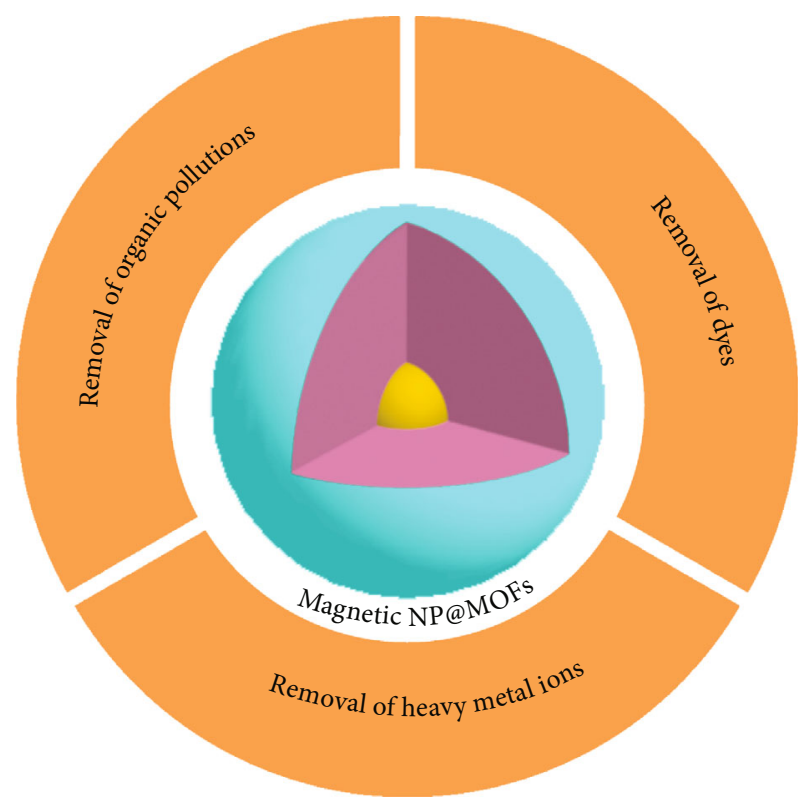

Figure 1: Schematic illustration of magnetic NP@MOF heterostructure for hazardous contaminant removal from the environment.

strated as an immobilization vector for enzymes [27]. $\mathrm{Fe}_{3} \mathrm{O}_{4}$ NPs were functionalized by the polydopamine (PDA) layer, and then $\mathrm{Cu}_{3}(\mathrm{btc})_{2}$ was synthesized on the surface of $\mathrm{Fe}_{3} \mathrm{O}_{4} @ \mathrm{PDA}$ by introducing $\mathrm{Fe}_{3} \mathrm{O}_{4} @ \mathrm{PDA}$ into an ethanol solution containing copper acetate and 1,3,5-benzenetricarboxylic acid (Figure 2). The MOF shell has a large surface area to ensure high load carrying capacity. Due to the strong affinity for the enzyme, the $\mathrm{Fe}_{3} \mathrm{O}_{4} @ \mathrm{PDA} @\left[\mathrm{Cu}_{3}(\mathrm{btc})_{2}\right]-$ enzyme composites achieved excellent digestion efficiency, good reusability, durability, and reproducibility.

2.2. Step-by-Step Method. Our group fabricated a series of $\mathrm{Fe}_{3} \mathrm{O}_{4} @ M O F s$ (e.g., $\mathrm{Fe}_{3} \mathrm{O}_{4} @ \mathrm{Cu}_{3}(\mathrm{btc})_{2}, \mathrm{Fe}_{3} \mathrm{O}_{4} @ M I L-100(\mathrm{Fe})$, and $\mathrm{Au}-\mathrm{Fe}_{3} \mathrm{O}_{4} @ \mathrm{MIL}-100(\mathrm{Fe})$ ) core-shell nanocomposites with a controllable MOF shell thickness by the versatile step-by-step strategy (Figure 3) [28-30]. Functionalization of magnetic $\mathrm{Fe}_{3} \mathrm{O}_{4}$ core with the mercaptoacetic acid (MAA) before the coating process was vitally important during the initial stage of the step-by-step assembly, because no core-shell structures could be obtained using the unfunctionalized magnetic $\mathrm{Fe}_{3} \mathrm{O}_{4}$ core [28]. The growth of MOF shell on the MAA-functionalized $\mathrm{Fe}_{3} \mathrm{O}_{4}$ core can be initiated by first the metal ions binding to the MAA on the $\mathrm{Fe}_{3} \mathrm{O}_{4}$ surface, to which then the organic ligands from the solution bind. The thickness of the MOF shell can be facile controlled by tuning the number of step-by-step assembly cycles. Zhang et al. also prepared the novel porous $\mathrm{Fe}_{3} \mathrm{O}_{4} @ \mathrm{MIL}-100(\mathrm{Fe})$ core-shell nanospheres by this method to achieve large enrichment capacity and high size exclusion selectivity for phosphopeptides [31].

2.3. Self-Template Method. In the self-template method, the magnetic metal or metal oxide composites will provide metal ions by sacrificing themselves and then coordinate to organic ligand. For example, $\mathrm{Fe}_{3} \mathrm{O}_{4} @ \mathrm{SiO}_{2} @ H K U S T-1$ magnetic core- 


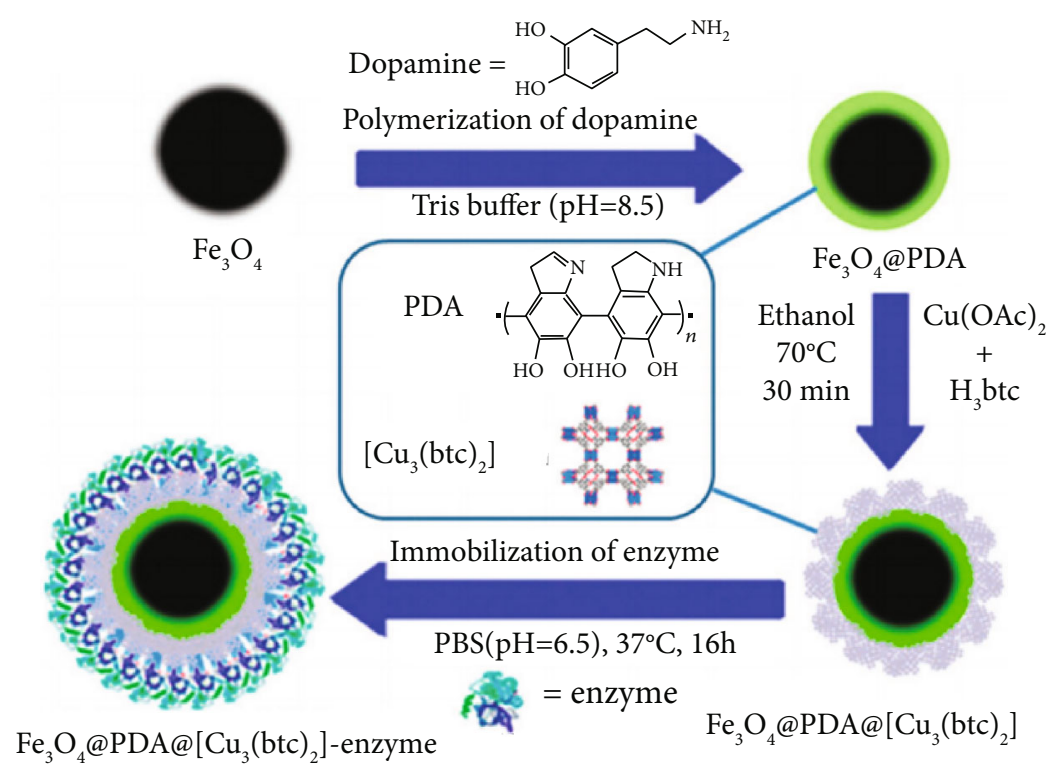

FIgure 2: Schematic illustration of $\mathrm{Fe}_{3} \mathrm{O}_{4} @ P D A @\left[\mathrm{Cu}_{3}(\mathrm{btc})_{2}\right]$ microspheres and the procedure for enzyme immobilization. Reprinted from Ref. [27] with permission of the Royal Society of Chemistry.

shell composite has been obtained by the self-template strategy in which magnetic $\mathrm{Fe}_{3} \mathrm{O}_{4} @ \mathrm{SiO}_{2}$ were first coated with $\mathrm{Cu}(\mathrm{OH})_{2}$ shell as the sacrificial template and then HKUST-1 grew around the core [32]. Here, $\mathrm{Cu}(\mathrm{OH})_{2}$ shell not only was the sacrificial template but also provides copper ion sources for the formation of HKUST-1 [32]. Compared to other template strategies, this approach shows decisive economy advantage and does not require additional surface modification. Moreover, the Bi-I-functionalized $\mathrm{Fe}_{3} \mathrm{O}_{4} @$ $\mathrm{SiO}_{2} @ H K U S T-1$ magnetic composite exhibited excellent adsorption for $\mathrm{Hg}^{2+}$ from water (Figure 4). By using this method, Cai and coworkers also reported the novel magnetic Prussian blue (PB) composite using the self-template method [33]. PB cube was used both as the sacrificial template and as the iron source of $\mathrm{Fe}_{3} \mathrm{O}_{4}$ for the formation of $\mathrm{PB}-\mathrm{Fe}_{3} \mathrm{O}_{4}$ composite.

2.4. Dry Gel Conversion Method. Tan et al. demonstrated a dry gel conversion (DGC) method to fabricate HKUST$1 / \mathrm{Fe}_{3} \mathrm{O}_{4}$ composites for desulfurization and denitrogenation applications [34]. In this method, the solvent is first separated from the mixed $\mathrm{Fe}_{3} \mathrm{O}_{4}$ and $\mathrm{MOF}$ precursors, and then solvent vapor is generated into the mixture to induce MOF formation around magnetic NPs. With this simple method, HKUST-1/ $\mathrm{Fe}_{3} \mathrm{O}_{4}$ composites have been successfully constructed without blockage of the MOF pores (Figure 5). Significantly, the obtained magnetic porous adsorbents not only can undergo efficient adsorption of various aromatic sulfur and nitrogen compounds from model fuels but also can be easily separated from mixture by an external magnetic field.

\section{Applications of Magnetic NP@MOF Composites in the Environment}

MOF-based magnetic nanostructures have been widely used for many applications due to their outstanding physicochem- ical performance [24]. In this review, we are particularly interested in applying these magnetic composites as sustainable environment adsorbents. Environmental pollution has become one of the major problems worldwide at present. Due to the decline of water quality, water bodies continue to deteriorate, leading to the suspension of relevant factories and agricultural production. The adverse social impact and economic loss caused threaten the sustainable development of society and the healthy development of mankind. There are a large number of organic, inorganic, and biological pollutants in water and soil, such as herbicides [35] and dyes [36]. The advantages of magnetic NP@MOF composites for the adsorption of hazardous materials from the environment will be discussed in later sections. Further, we will also point out the state-of-the-art progress in magnetic NP@MOF composite adsorption applications categorized by the hazardous compound type.

3.1. Adsorption of Organic Contaminants. Magnetic NP@MOF composites are promising porous adsorbents for the adsorption of organic contaminants from the environment due to their magnetic core for easy magnetic separation along with porous MOF shell for highly selective removal of contaminants. For example, Zhou et al. developed a novel magnetic $\mathrm{Fe}_{3} \mathrm{O}_{4} @ \mathrm{MIL}-100(\mathrm{Fe})$ NPs for mechanochemical magnetic solid phase extraction (MCMSPE) of organochlorine pesticides from tea leaves [37]. $\mathrm{Fe}_{3} \mathrm{O}_{4} @ \mathrm{MIL}-100(\mathrm{Fe})$ magnetic NPs were synthesized by the step-by-step method and further successfully used for the separation of organochlorine pesticides from tea. Moreover, $\mathrm{Fe}_{3} \mathrm{O}_{4} @ \mathrm{MIL}-100(\mathrm{Fe})$ magnetic NPs can be reused with no significant changes in the organochlorine pesticide recovery after five adsorption cycles. The results indicated that such magnetic NPs are ideal recyclable adsorbents for removal of organochlorine pesticides from plant samples. In the same time, $\mathrm{Fe}_{3} \mathrm{O}_{4} @$ $\mathrm{SiO}_{2} @ \mathrm{Zr}-\mathrm{MOF}$ magnetic composites were also reported for 


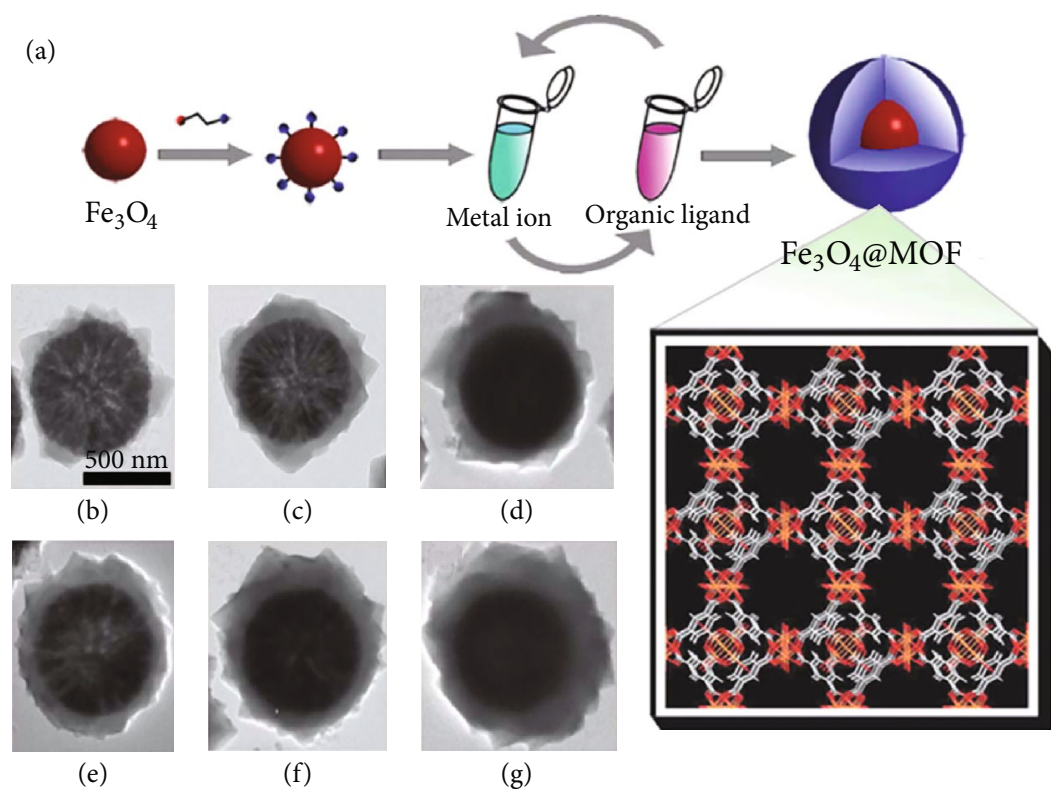

FIGURE 3: Schematic representation of the step-by-step assembly strategy (a) and TEM images of $\mathrm{Fe}_{3} \mathrm{O}_{4} @\left[\mathrm{Cu}_{3}(\mathrm{btc})_{2}\right]$ core-shell magnetic microspheres after (b) 10, (c) 20, (d) 25, (e) 30, (f) 40, and (g) 50 assembly cycles at $25^{\circ} \mathrm{C}$. Reprinted from Ref. [28] with permission of the Royal Society of Chemistry.

the effective removal of pharmaceutical compounds from water [38]. The obtained $\mathrm{Fe}_{3} \mathrm{O}_{4} @ \mathrm{SiO}_{2} @ U i O-66-\mathrm{NH}_{2}$ displayed a high adsorption capacity and rapid separation rate for the adsorption of salicylic acid (SA) and acetylsalicylic acid (ASA) due to the magnetic NPs in combination with porous $\mathrm{Zr}-\mathrm{MOF}$ (Figure 6). The saturated magnetization value of $\mathrm{Fe}_{3} \mathrm{O}_{4} @ \mathrm{SiO}_{2} @ \mathrm{UiO}-66-\mathrm{NH}_{2}$ was measured to be $25.4 \mathrm{emu} \mathrm{g}^{-1}$. The easy separation, high capacities, and reusability of the magnetic Zr-based MOF make it as superior adsorbents for removal of pharmaceutical contaminants.

Based on a similar process, four other magnetic composites, magG@SiO $@$ @IF-8 [39], $\mathrm{Fe}_{3} \mathrm{O}_{4} @ \mathrm{SiO}_{2} @ \mathrm{MOF} / \mathrm{TiO}_{2}$ [40], Fe@SiO $@$ @OF-5 [41], and $\mathrm{Fe}_{3} \mathrm{O}_{4} @ \mathrm{~m}-\mathrm{SiO}_{2} / \mathrm{PSA} @ \mathrm{Zr}-$ MOF [42], were successfully synthesized based on the magnetic NPs coated with a layer of $\mathrm{SiO}_{2}$. The magnetic $\mathrm{NPs@SiO}{ }_{2}$ cores help adsorption of metal ions and organic linkers for the growth of outer shell of MOF layers. The magG@SiO ${ }_{2} @ Z I F-8$ composites displayed high extraction efficiency and reusability for adsorption of phthalate esters with the linear range of $50-8000 \mathrm{ng} \mathrm{mL}^{-1}$ and up to $92 \%$ recoveries [39]. $\mathrm{Fe}_{3} \mathrm{O}_{4} @ \mathrm{SiO}_{2} @ \mathrm{MOF} / \mathrm{TiO}_{2}$ [40] and Fe@S$\mathrm{iO}_{2} @$ MOF-5 [41] core-shell nanocomposites were used as efficient adsorbents for MSPE of five triazole fungicides as well as $\mathrm{N}$ - and S-containing polycyclic aromatic hydrocarbons from contaminated water. Here, $\mathrm{TiO}_{2}$ immobilized on the surface of $\mathrm{Fe}_{3} \mathrm{O}_{4} @ \mathrm{SiO}_{2} @ \mathrm{MOF}$ could enhance the adsorption properties of magnetic MOF with the detection and quantification limits of $0.19-1.20 \mathrm{ng} \mathrm{L}^{-1}$ and 0.61-3.62 ng L ${ }^{-1}$, respectively [40]. The $\mathrm{Fe} @ S i O_{2} @ \mathrm{MOF}-5$ exhibited a good adsorption for $\mathrm{N}$ - and S-containing polycyclic aromatic hydrocarbons with LODs in the range of 0.025 $0.033 \mu \mathrm{gL}^{-1}$ [41]. In addition to these, $\mathrm{Xu}$ and coworkers developed a novel $\mathrm{Fe}_{3} \mathrm{O}_{4} @ \mathrm{~m}-\mathrm{SiO}_{2} / \mathrm{PSA} @ \mathrm{Zr}$-MOF magnetic nanocomposite for bifenthrin determination from water [42]. Considering the outstanding performance and limitless of MOFs, it is expected that such MOF-based magnetic coreshell nanocomposites will open a new doorway in the field of adsorption of organic contaminants from the environment.

3.2. Adsorption of Dyes from Wastewater. Dye has become an important industrial hazardous contaminant in water. In recent years, with the development of the dye industry, it has a great adverse impact on the environment and human health. Therefore, it is crucial to devise a strategy for the treatment and removal of these dyes from polluted water. Wang et al. reported the use of magnetic $\mathrm{Fe}_{3} \mathrm{O}_{4}$ /MIL$101(\mathrm{Cr})$ composite for effective adsorption of two dyes, acid red 1 (AR1) and orange $\mathrm{G}(\mathrm{OG})[6]$. They fabricated $\mathrm{Fe}_{3} \mathrm{O}_{4} /$ MIL-101(Cr) magnetic composites by a reductionprecipitation method with large surface areas, strong magnetism, and excellent dispersion effect. The adsorption capacities of AR1 and OG with $\mathrm{Fe}_{3} \mathrm{O}_{4} / \mathrm{MIL}-101(\mathrm{Cr})$ were 142.9 and $200.0 \mathrm{mg} \mathrm{g}^{-1}$, respectively [6]. The authors suggested that the adsorption of AR1 and OG was spontaneous, exothermic, and randomness decreased with monolayer adsorption during this process. Very recently, perfect $\mathrm{MgFe}_{2} \mathrm{O}_{4} @ \mathrm{MOF}$ [43] and $\mathrm{Fe}_{3} \mathrm{O}_{4} @ \mathrm{SiO}_{2} @ \mathrm{Zn}$-TDPAT [44] core-shell magnetic materials were reported by the presynthesized magnetic NP template method. The $\mathrm{MgFe}_{2} \mathrm{O}_{4} @ \mathrm{MOF}$ magnetic composites were fabricated by a mercaptoacetic acid- (MAA-) functionalized $\mathrm{MgFe}_{2} \mathrm{O}_{4} \mathrm{NPs}$ as the template method [43]. The obtained $\mathrm{MgFe}_{2} \mathrm{O}_{4} @ \mathrm{MOF}$ hybrid nanomaterials displayed excellent removal of Rhodamine B (RB, $219.78 \mathrm{mg} \mathrm{g}^{-1}$ ) and Rhodamine $6 \mathrm{G}\left(\mathrm{Rh} 6 \mathrm{G}, 306.75 \mathrm{mg} \mathrm{g}^{-1}\right.$ ) from wastewater. Moreover, these magnetic hybrid nanomaterials showed good reusability even after 10 times reused. The as-synthesized $\mathrm{Fe}_{3} \mathrm{O}_{4} @ \mathrm{SiO}_{2} @ \mathrm{Zn}$-TDPAT core-shell magnetic material also displayed a high performance activity in adsorption of polluted dyes [44]. The adsorption efficiencies can reach 100 and $99 \%$ for Congo red (CR) and methylene blue (MB) by this 


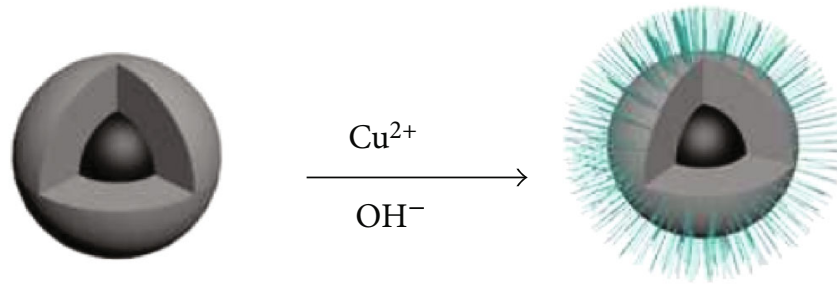

$\mathrm{Fe}_{3} \mathrm{O}_{4} @ \mathrm{SiO}_{2}$
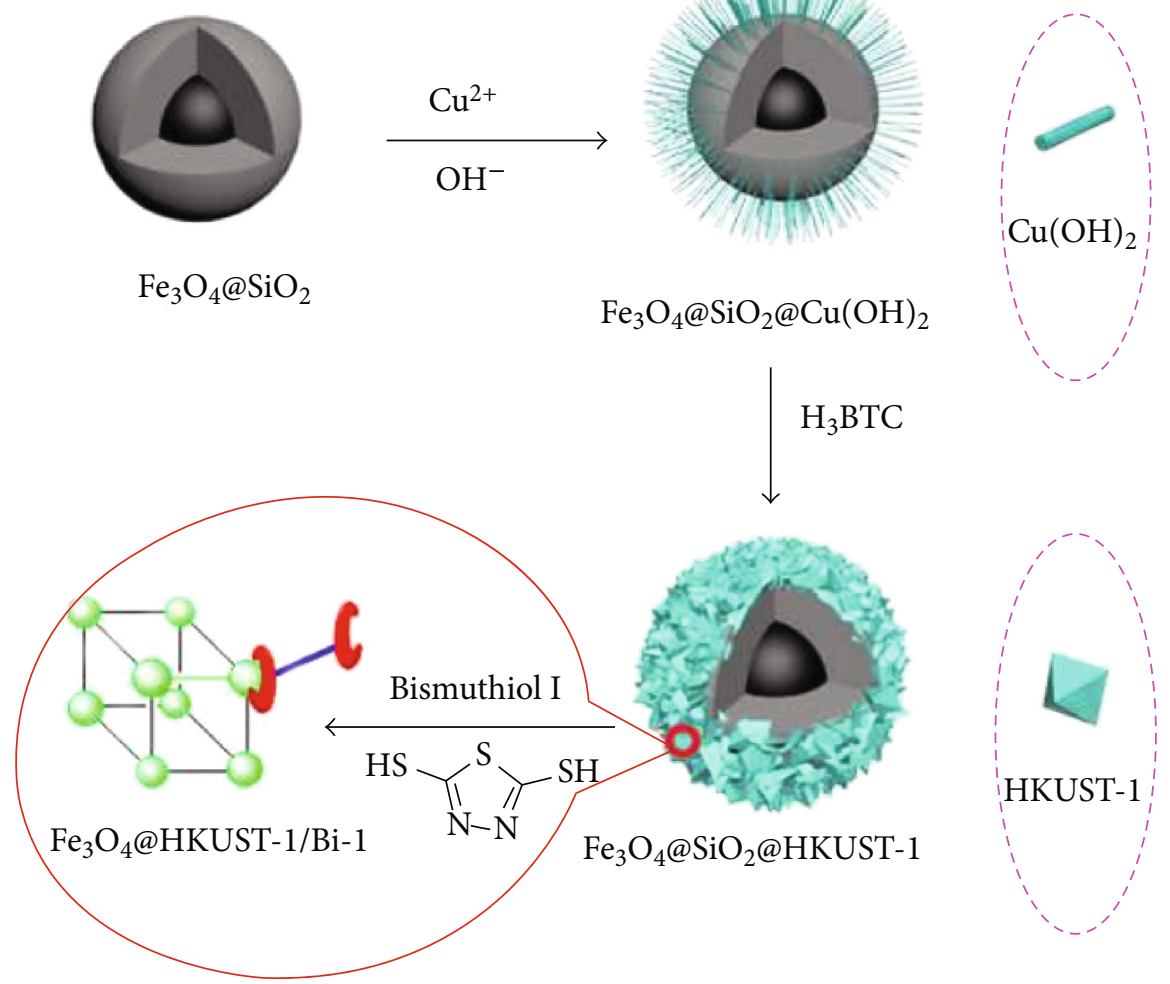

FIgURE 4: Scheme of the preparation of Bi-I functionalized $\mathrm{Fe}_{3} \mathrm{O}_{4} @ \mathrm{SiO}_{2} @ \mathrm{HKUST}-1$ composites. Reprinted from Ref. [32] with permission of the Royal Society of Chemistry.

magnetic material, respectively. Significantly, such $\mathrm{Fe}_{3} \mathrm{O}_{4} @$ $\mathrm{SiO}_{2} @ \mathrm{Zn}$-TDPAT core-shell magnetic material can be stable under different acid-alkaline conditions. The results suggested that MOF-based magnetic core-shell materials are promising adsorbents for dye removal from wastewater.

These MOF-based magnetic composites have high capacity toward a certain dye; the application of selective removal of specific dye from a mixture of multiple dye-polluted water needs more development. In 2018, Yang et al. reported a novel $\mathrm{Fe}_{3} \mathrm{O}_{4}$-PSS@ZIF-67 magnetic core-shell composite for selective adsorption of methyl orange (MO) from $\mathrm{MO}$ and methylene blue (MB) mixed solution (Figure 7) [45]. The results demonstrated that the adsorption capacity of the magnetic composites for $\mathrm{MO}$ was measured to be $738 \mathrm{mg} \mathrm{g}^{-1}$ with the separation rate of up to $92 \%$. The selective adsorption mechanism can be attributed to chargeselectivity between the dye molecule and the MOF. The sizes of the $\mathrm{MO}$ and $\mathrm{MB}$ molecules are $1.54 \times 0.48 \times 0.28 \mathrm{~nm}^{3}$ and $1.38 \times 0.64 \times 0.21 \mathrm{~nm}^{3}$, while ZIF-67 has pore cage of $1 \mathrm{~nm}$. Therefore, $\mathrm{MO}$ and $\mathrm{MB}$ molecules can be adsorbed in the pore cage of $\mathrm{Fe}_{3} \mathrm{O}_{4}$-PSS@ZIF-67. Furthermore, the negatively charged $\mathrm{MO}$ can be adsorbed with the Lewis base of $\mathrm{Co}^{2+}$ centrals because of the electrostatic attraction while the positively charged $\mathrm{MB}$ is hard to be adsorbed because of the electrostatic repulsion.

3.3. Adsorption of Heavy Metal Ions. Recently, MOF-based magnetic composites have been also used as porous adsor- bents for the removal of heavy metal ions from the environment. MOF-based magnetic composites are promising adsorbents for the removal of heavy metal ions because of their easy modification and isolation. Karimi et al. reported a chemical bond between the $\mathrm{NHSO}_{3} \mathrm{H}$-functionalized $\mathrm{Fe}_{3} \mathrm{O}_{4}$ and the HKUST-1 method for the synthesis of magnetic $\mathrm{Fe}_{3} \mathrm{O}_{4}$-NHSO $\mathrm{NH}_{3} \mathrm{H} @ \mathrm{HKUST}-1$ nanocomposites for the adsorption of lead ions $\left(\mathrm{Pb}^{2+}\right)$ from wastewater [46]. According to this work, the maximum adsorption capacity of $\mathrm{Pb}^{2+}$ with $\mathrm{Fe}_{3} \mathrm{O}_{4}$-NHSO ${ }_{3} \mathrm{H} @ H K U S T-1$ was $384.6 \mathrm{mgg}^{-1}$, which corresponds to $46.3 \%$ of the magnetic adsorbent occupied sites. After the adsorbent is separated by the magnet and washed with $0.1 \mathrm{M}$ of $\mathrm{HCl}$ and distilled water, it can be used for another adsorption experiment. As a result, $\mathrm{Fe}_{3} \mathrm{O}_{4}$ $\mathrm{NHSO}_{3} \mathrm{H} @ \mathrm{HKUST}-1$ could be reused four times without significant loss of adsorption activity (>90\%). Huang et al. reported two amino-modified Zr-based magnetic MOF composites $\left(\mathrm{Fe}_{3} \mathrm{O}_{4} @ \mathrm{SiO}_{2} @ \mathrm{UiO}-66-\mathrm{NH}_{2}\right.$ and $\mathrm{Fe}_{3} \mathrm{O}_{4} @ \mathrm{SiO}_{2} @$ UiO-66-Urea) for the extraction of heavy metal ions [47]. $\mathrm{Fe}_{3} \mathrm{O}_{4} @ \mathrm{SiO}_{2} @ \mathrm{UiO}-66-\mathrm{NH}_{2}$ and $\mathrm{Fe}_{3} \mathrm{O}_{4} @ \mathrm{SiO}_{2} @ U i O-66-U r e a$ were prepared by a simple one-pot strategy with different precursors. The obtained amine-decorated magnetic composites exhibited high adsorption for heavy metal ions compared to pure magnetic composites. In particular, $\mathrm{Fe}_{3} \mathrm{O}_{4} @ \mathrm{SiO}_{2} @ \mathrm{UiO}-$ 66- $\mathrm{NH}_{2}$ showed the highest adsorption capacity for $\mathrm{Pb}^{2+}$ $\left(102 \mathrm{mg} \mathrm{g}^{-1}\right)$. The authors concluded that the improvement in the removal of $\mathrm{Pb}^{2+}$ by the amine-decorated magnetic composites compared with $\mathrm{Fe}_{3} \mathrm{O}_{4} @ \mathrm{SiO}_{2} @ \mathrm{UiO}-66$ is due to 


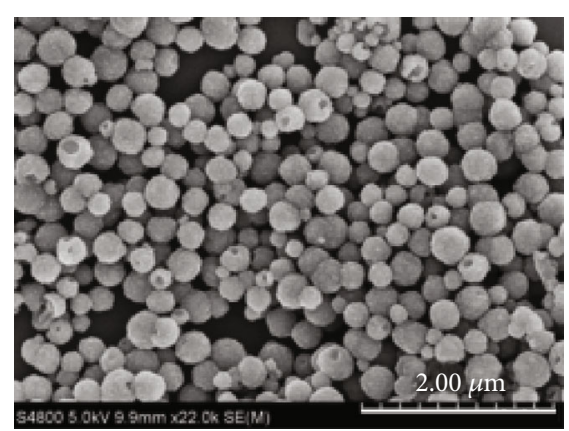

(a)

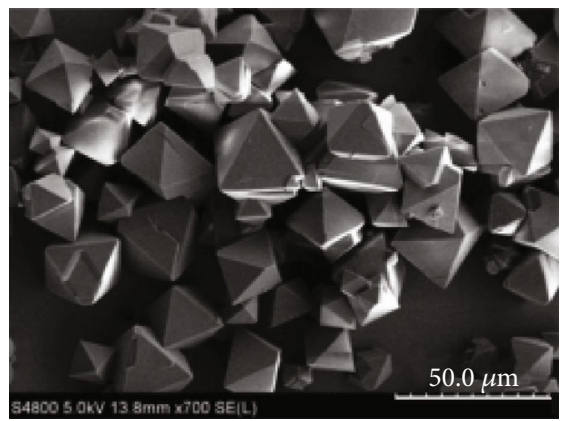

(c)

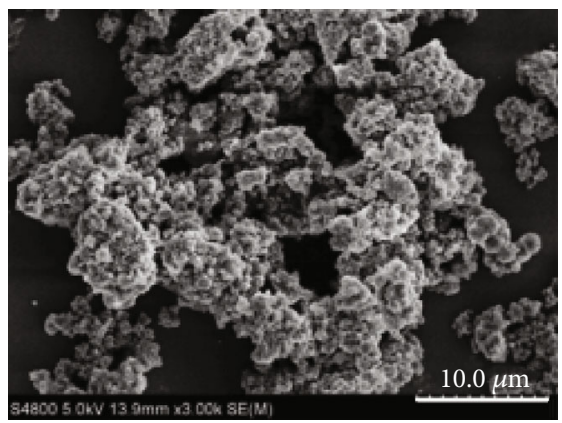

(e)

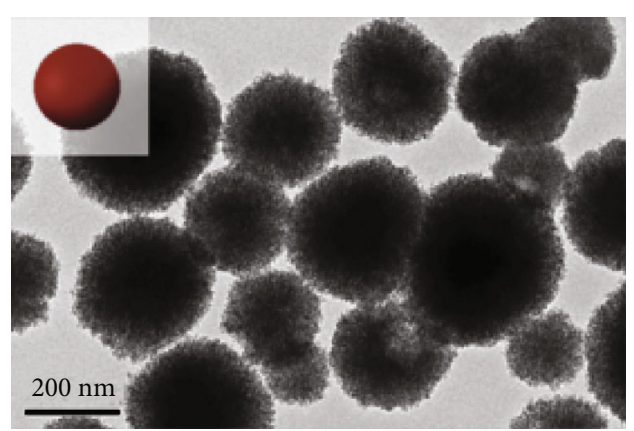

(b)

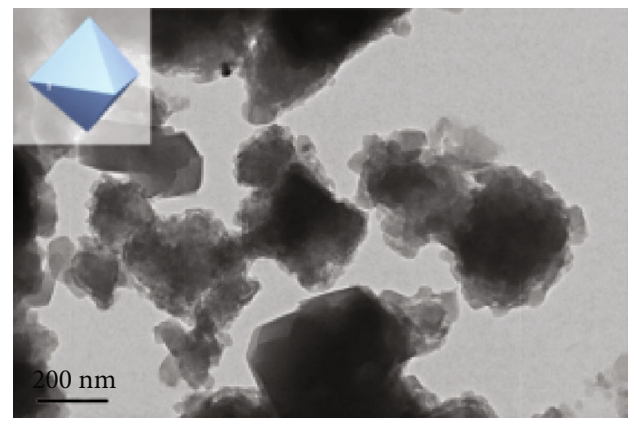

(d)

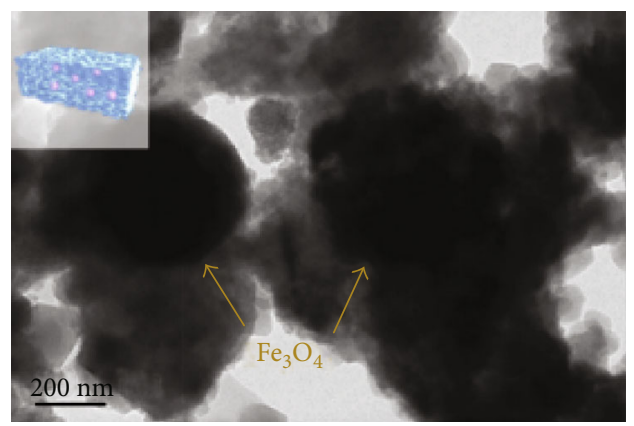

(f)

Figure 5: SEM and TEM images of $(\mathrm{a}, \mathrm{b}) \mathrm{Fe}_{3} \mathrm{O}_{4}$, (c, d) HKUST-1, and (e, f) the HKUST-1/ $\mathrm{Fe}_{3} \mathrm{O}_{4}$ composites. Reprinted from Ref. [34] with permission of Elsevier.

the fact that the $-\mathrm{NH}_{2}$ groups on the magnetic composites provide more binding sites for the adsorption of $\mathrm{Pb}^{2+}$ by chelating. Further, hierarchically HPU-13@ $\mathrm{Fe}_{3} \mathrm{O}_{4}$ (HPU-13= $\left\{\left[\mathrm{Cu}_{3}(\mathrm{~L})_{2}\right] \cdot \mathrm{OH} \cdot 2 \mathrm{CH}_{3} \mathrm{CH}_{2} \mathrm{OH} \cdot 10 \mathrm{H}_{2} \mathrm{O}\right\} n ; \mathrm{HL}=2$-(5-pyridin-4yl-2H-[1,2,4]triazol-3-yl)pyrimidine) magnetic hybrid composites were synthesized for high removal and excellent reuse of $\mathrm{Cr}(\mathrm{VI})$ ions from water [48]. HPU-13@ $\mathrm{Fe}_{3} \mathrm{O}_{4}$ showed high adsorption capacities for $\mathrm{Cr}_{2} \mathrm{O}_{7}{ }^{2-}\left(398.41 \mathrm{mgg}^{-1}\right)$ and $\mathrm{CrO}_{4}{ }^{2-}$ $\left(471.69 \mathrm{mg} \mathrm{g}^{-1}\right)$. The results proved that oxidation of $\mathrm{Cu}(\mathrm{I})$ to $\mathrm{Cu}(\mathrm{II})$ on the magnetic adsorbents occurred during the adsorption process and partial reduction of $\mathrm{Cr}$ (VI) to $\mathrm{Cr}$ (III) in the solution at the same time. Finally, the authors revealed that the high adsorption of $\mathrm{Cr}(\mathrm{VI})$ under these conditions is due to the synergistic reaction of $\mathrm{Cr}(\mathrm{VI})$ reduction and adsorption [48].

The radioactive elements are also a major issue to the environment such as $\mathrm{U}(\mathrm{VI})$ and $\mathrm{Th}(\mathrm{IV})$. These radioactive metal ions can create numerous diseases including liver and lung cancers. In this case, the adsorption of these metal ions from the environment is a challenge and critical issue for the environmental remediation. Alqadami et al. prepared an Al-based magnetic MOF nanocomposite $\left(\mathrm{Fe}_{3} \mathrm{O}_{4} @ A M C A-\right.$ MIL53(Al)) for the adsorption of $\mathrm{U}(\mathrm{VI})$ and $\mathrm{Th}(\mathrm{IV})$ from wastewater [49]. The adsorption capacities for U(VI) and Th(IV) were measured to be 227.3 and $285.7 \mathrm{mg} \mathrm{g}^{-1}$, respectively. The adsorption equilibrium time of $\mathrm{Fe}_{3} \mathrm{O}_{4} @ A M C A-$ MIL53(Al) for both radioactive metal ions was demonstrated within $90 \mathrm{~min}$. The results suggested the adsorption mechanism for U(VI) and Th(IV) over $\mathrm{Fe}_{3} \mathrm{O}_{4} @ A M C A-M I L 53(\mathrm{Al})$ through the electrostatic interactions between the organic part of the magnetic nanocomposite and the radioactive metal ions and coordinate interactions between the metal ions and nitrogen in the framework. Min et al. reported a novel $\mathrm{Fe}_{3} \mathrm{O}_{4} @ \mathrm{ZIF}-8$ magnetic nanocomposite for selective removal of $\mathrm{UO}_{2}{ }^{2+}$ from water, which showed a high adsorption capacity of $523.5 \mathrm{mg} \mathrm{Ug}^{-1}$ [50]. Furthermore, 


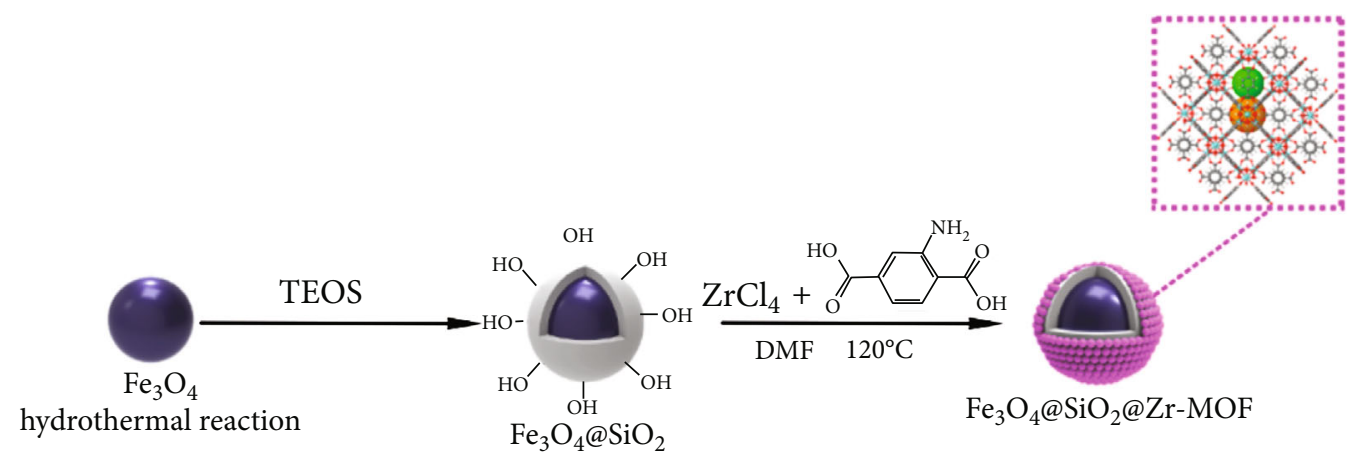

(a)

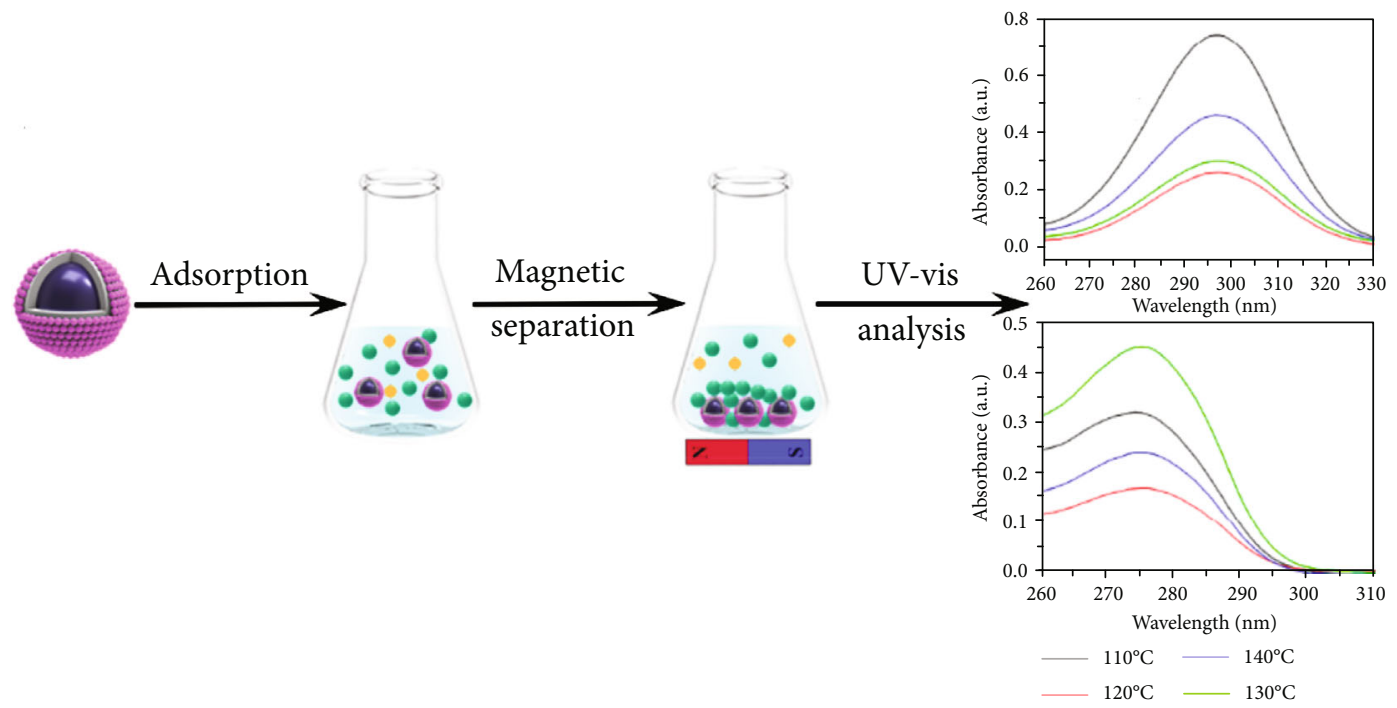

(b)

FIGURE 6: Scheme of (a) the preparation of $\mathrm{Fe}_{3} \mathrm{O}_{4} @ \mathrm{SiO}_{2} @ \mathrm{Zr}-\mathrm{MOF}$ composites and (b) the adsorption of SA and ASA. Reprinted from Ref. [38] with permission of the American Chemical Society.

the selective separation of the $\mathrm{UO}_{2}{ }^{2+}$ from lanthanide results indicated that the obtained $\mathrm{Fe}_{3} \mathrm{O}_{4} @ \mathrm{ZIF}-8$ displayed remarkable selectivity performance for $\mathrm{UO}_{2}{ }^{2+}$ in the presence of lanthanides at $\mathrm{pH} 3$.

Selectivity is one of the most primary issues of a good adsorbent in the practical application. In order to solve this problem, magnetic adsorbents can be modified by various functional groups for the removal of target metal ions. The functional groups can be easily introduced into the MOF-based magnetic composites by a facile postsynthetic modification (PSM) method. Very recently, we prepared thiol-functionalized $\mathrm{Fe}_{3} \mathrm{O}_{4} @ \mathrm{Cu}_{3}(\mathrm{btc})_{2}$ core-shell magnetic microspheres and investigated their application in selective adsorption of heavy metal ions in the presence of other background ions from water [51]. $\mathrm{Fe}_{3} \mathrm{O}_{4} @ \mathrm{Cu}_{3}(\mathrm{btc})_{2}$ core-shell magnetic microspheres were synthesized by a step-by-step assembly fashion. Further, $\mathrm{Cu}_{3}(\mathrm{btc})_{2}$ shell of the magnetic microspheres was modified by thiol groups of dithioglycol using such PSM method (Figure 8). Significantly, the thiolfunctionalized $\mathrm{Fe}_{3} \mathrm{O}_{4} @ \mathrm{Cu}_{3}(\mathrm{btc})_{2}$ showed high selective adsorption for $\mathrm{Pb}^{2+}\left(K_{\mathrm{d}}=1.23 \times 10^{4} \mathrm{mLg}^{-1}\right)$ and $\mathrm{Hg}^{2+}$ $\left(K_{\mathrm{d}}=5.98 \times 10^{4} \mathrm{~mL} \mathrm{~g}^{-1}\right)$ in the presence of background ions of $\mathrm{Ni}^{2+}, \mathrm{Na}^{+}, \mathrm{Mg}^{2+}, \mathrm{Ca}^{2+}, \mathrm{Zn}^{2+}$, and $\mathrm{Cd}^{2+}[51]$.

\section{Adsorption Mechanism}

The adsorption method is widely accepted for the removal of hazardous pollutants from the environment [52]. Magnetic MOF composites are superior to the traditional porous materials, due to their rational design, tunable porosity, controllable dimensions, large internal surface area, and easy isolation. Particularly, the pore shape and size of the magnetic MOFs can be controlled to selective adsorption of targeted hazardous molecules [53]. The mechanism for the removal of hazardous pollutants can be summarized as the four major types [17, 53]: (I) The hazardous molecules can be bound to the coordinatively unsaturated metal centers of magnetic MOFs. (II) The hazardous molecules can be adsorbed by $\pi-\pi$ stacking interactions between the organic part of the MOFs and the hazardous molecules. (III) There are electrostatic interactions between the hazardous molecules and the magnetic MOFs. (IV) There is molecule bonding between the decorate functional groups on ligands of magnetic MOFs and the hazardous molecules. With the rapid new multifunctional MOF development, the mechanisms for the adsorption of pollutants over the magnetic MOFs become increasingly clear. 


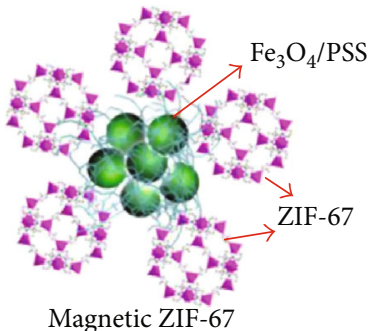

Magnetic ZIF-67 (1) Adding $M$

(2) Adsorption

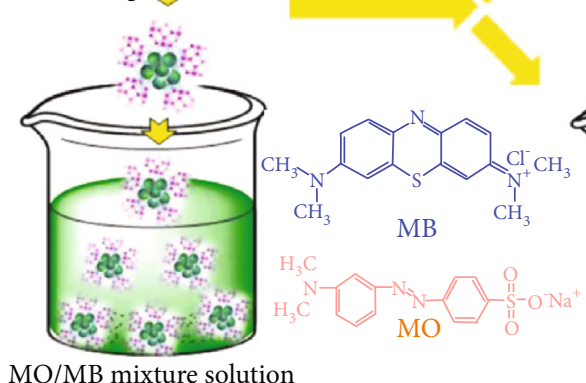

(a)

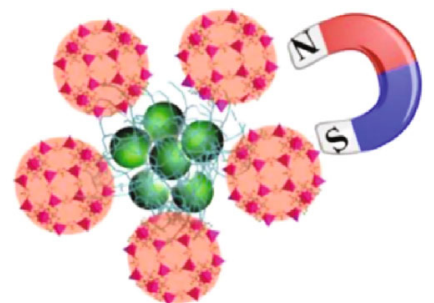

MO@magnetic ZIF-67 น(3) Separation

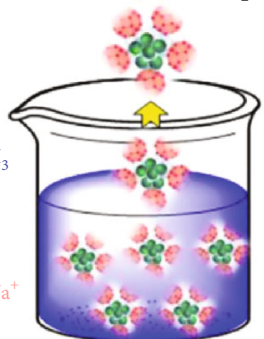

Residual MB solution

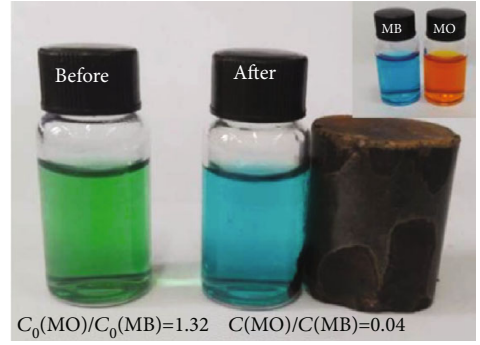

(b)

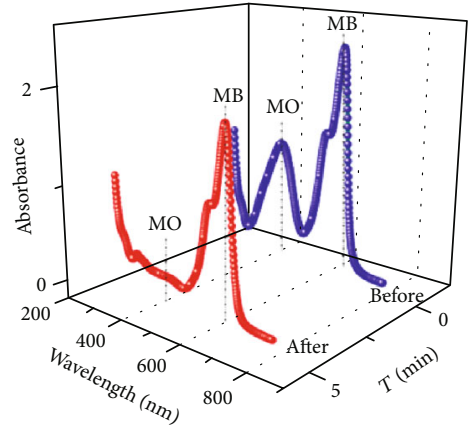

(c)

Figure 7: (a) Scheme of selective adsorption of MO from the mixed MO/MB solution by $\mathrm{Fe}_{3} \mathrm{O}_{4}$-PSS@ZIF-67 magnetic composites; photographs (b) and UV-vis spectra (c) of the mixed MO/MB solution before and after magnetic separation. Reprinted from Ref. [45] with permission of Elsevier.
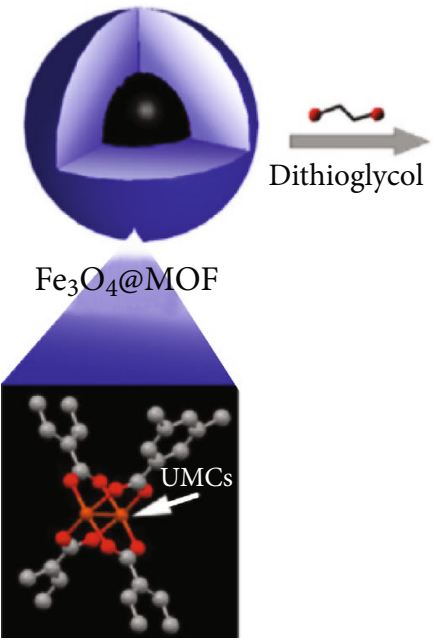

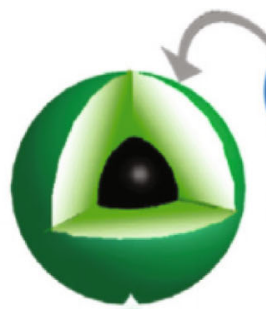

$\mathrm{Fe}_{3} \mathrm{O}_{4} @ \mathrm{MOF}-\mathrm{SH}$

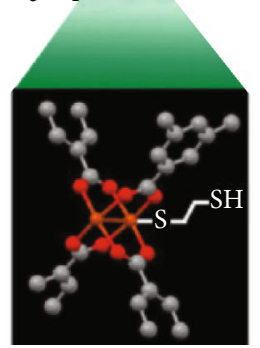

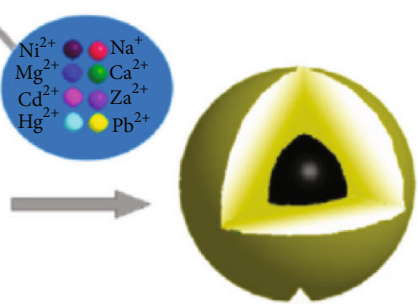

$\mathrm{Fe}_{3} \mathrm{O}_{4} @ M O F-\mathrm{S}-\mathrm{Hg} / \mathrm{Pb}$

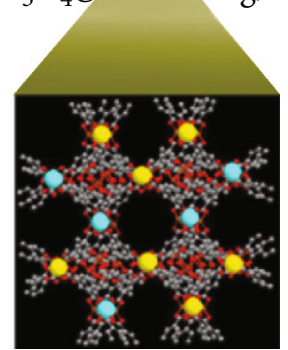

Figure 8: Scheme of the preparation of thiol-functionalized $\mathrm{Fe}_{3} \mathrm{O}_{4} @ \mathrm{Cu}_{3}(\mathrm{btc})_{2}$ and its use for selective removal of $\mathrm{Pb}^{2+}$ and $\mathrm{Hg}^{2+}$ from the mixed heavy metal ion solution. Reprinted from Ref. [51] with permission of Elsevier.

\section{Conclusion and Outlook}

Here, we summarize a review of recent developments in the MOF-based magnetic nanocomposites for the removal of hazardous contaminants from the environment. The design and synthesis of the magnetic core-shell MOF composites are promising methods to achieve synergies of magnetic particle core and porous MOF shell. Compared with traditional adsorption materials, magnetic MOF adsorbents have a larger specific surface area and more surface active sites and can be quickly and easily recovered by an external magnetic field, which is in line with the modern green concept. Because of these excellent properties, magnetic MOF adsorbents have great application prospects in the removal of hazardous materials from the environment. The magnetic MOF composites with highly selective adsorption of target toxic compounds can be constructed by chemical modification, which will further improve the removal efficiency. This review has demonstrated several synthetic methods for the MOF-based magnetic core-shell composites. However, the 
current challenge is that most of the reported magnetic MOFs are still in the small-scale application stage and the far distance from large-scale industrial production and application to safeguard the environment. In addition, the incorporated magnetic particle shape and size are highly desirable, which are key issues for the application in adsorption with high capacity and selectivity. Meanwhile, the understanding of the electronic structure and interactions present between the magnetic core and MOF shell remains a challenge. Furthermore, the exact mechanism of enhanced adsorption activity by the magnetic MOF composites is still unclear. Although challenges still exist, it is expected that with the in-depth development and discussion of the magnetic MOF composites at home and abroad, it will show a broad prospect in the future practical application.

\section{Conflicts of Interest}

The authors declare that they have no conflicts of interest.

\section{Authors' Contributions}

Gege Zhao and Nianqiao Qin contributed equally to this work.

\section{Acknowledgments}

This work was supported by the National Natural Science Foundation of China (NSFC, 21501003), Science and Technology Major Projects of Anhui Province (18030801104), Natural Science Foundation of Anhui Province (1608085QB27), National Undergraduate Training Programs for Innovation and Entrepreneurship of Anhui Agriculture University (201910364013), and Provincial Undergraduate Training Programs for Innovation and Entrepreneurship of Anhui Agriculture University (201810364080).

\section{References}

[1] T. Wen, J. Wang, S. Yu, Z. Chen, T. Hayat, and X. Wang, "Magnetic porous carbonaceous material produced from tea waste for efficient removal of $\mathrm{As}(\mathrm{V}), \mathrm{Cr}(\mathrm{VI})$, humic acid, and dyes," ACS Sustainable Chemistry \& Engineering, vol. 5, no. 5, pp. 4371-4380, 2017.

[2] H. M. Baker, A. M. Massadeh, and H. A. Younes, "Natural Jordanian zeolite: removal of heavy metal ions from water samples using column and batch methods," Environmental Monitoring and Assessment, vol. 157, no. 1-4, pp. 319-330, 2009.

[3] A. V. Desai, B. Manna, A. Karmakar, A. Sahu, and S. K. Ghosh, "A water-stable cationic metal-organic framework as a dual adsorbent of oxoanion pollutants," Angewandte Chemie International Edition, vol. 55, no. 27, pp. 7811-7815, 2016.

[4] P. Mondal, C. B. Majumder, and B. Mohanty, "Laboratory based approaches for arsenic remediation from contaminated water: recent developments," Journal of Hazardous Materials, vol. 137, no. 1, pp. 464-479, 2006.

[5] M. G. Khedr, "Nanofiltration of oil field-produced water for reinjection and optimum protection of oil formation," Desalination and Water Treatment, vol. 55, no. 12, pp. 3460-3468, 2015.
[6] T. Wan, P. Zhao, N. Lu, H. Chen, C. Zhang, and X. Hou, "Facile fabrication of $\mathrm{Fe}_{3} \mathrm{O}_{4} / \mathrm{MIL}-101(\mathrm{Cr})$ for effective removal of acid red 1 and orange G from aqueous solution," Chemical Engineering Journal, vol. 295, pp. 403-413, 2016.

[7] F. P. Almeida, M. B. S. Botelho, C. Doerenkamp et al., "Mesoporous aluminosilicate glasses: potential materials for dye removal from wastewater effluents," Journal of Solid State Chemistry, vol. 253, pp. 406-413, 2017.

[8] F. Ke, C. Peng, T. Zhang et al., "Fumarate-based metal-organic frameworks as a new platform for highly selective removal of fluoride from brick tea," Scientific Reports, vol. 8, no. 1, p. 939, 2018.

[9] J.-L. Gong, B. Wang, G.-M. Zeng et al., "Removal of cationic dyes from aqueous solution using magnetic multi-wall carbon nanotube nanocomposite as adsorbent," Journal of Hazardous Materials, vol. 164, no. 2-3, pp. 1517-1522, 2009.

[10] S. Liu, Y. Ding, P. Li et al., "Adsorption of the anionic dye Congo red from aqueous solution onto natural zeolites modifified with N,N-dimethyl dehydroabietylamine oxide," Chemical Engineering Journal, vol. 248, pp. 135-144, 2014.

[11] Q.-L. Zhu and Q. Xu, "Metal-organic framework composites," Chemical Society Reviews, vol. 43, no. 16, pp. 5468-5512, 2014.

[12] B. Boukoussa, F. Abidallah, Z. Abid et al., "Synthesis of polypyrrole/Fe-kanemite nanocomposite through in situ polymerization: effect of iron exchange, acid treatment, and $\mathrm{CO}_{2}$ adsorption properties," Journal of Materials Science, vol. 52, no. 5, pp. 2460-2472, 2017.

[13] X. Kuang, Y. Ma, H. Su, J. Zhang, Y.-B. Dong, and B. Tang, "High-performance liquid chromatographic enantioseparation of racemic drugs based on homochiral metal-organic framework," Analytical Chemistry, vol. 86, no. 2, pp. 1277$1281,2014$.

[14] R. Kaur, K. Vellingiri, K.-H. Kim, A. K. Paul, and A. Deep, "Efficient photocatalytic degradation of rhodamine $6 \mathrm{G}$ with a quantum dot-metal organic framework nanocomposite," Chemosphere, vol. 154, pp. 620-627, 2016.

[15] Q. Meng, X. Xin, L. Zhang, F. Dai, R. Wang, and D. Sun, "A multifunctional Eu MOF as a fluorescent $\mathrm{pH}$ sensor and exhibiting highly solvent-dependent adsorption and degradation of rhodamine B," Journal of Materials Chemistry A, vol. 3, no. 47, pp. 24016-24021, 2015.

[16] R. Ma, P. Yang, Y. Ma, and F. Bian, "Facile synthesis of magnetic hierarchical core-shell structured Fe3O4@PDAPd@MOF nanocomposites: highly integrated multifunctional catalysts," ChemCatChem, vol. 10, no. 6, pp. 1446-1454, 2018.

[17] N. A. Khan, Z. Hasan, and S. H. Jhung, "Adsorptive removal of hazardous materials using metal-organic frameworks (MOFs): a review," Journal of Hazardous Materials, vol. 244-245, pp. 444-456, 2013.

[18] S. Bao, K. Li, P. Ning, J. Peng, X. Jin, and L. Tang, "Synthesis of amino-functionalization magnetic multi-metal organic framework $\left(\mathrm{Fe}_{3} \mathrm{O}_{4} / \mathrm{MIL}-101\left(\mathrm{Al}_{0.9} \mathrm{Fe}_{0.1}\right) / \mathrm{NH}_{2}\right)$ for efficient removal of methyl orange from aqueous solution," Journal of the Taiwan Institute of Chemical Engineers, vol. 87, pp. 64-72, 2018.

[19] Z. Miao, X. Shu, and D. Ramella, "Synthesis of a

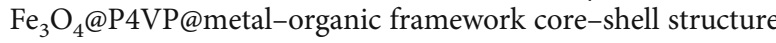
and studies of its aerobic oxidation reactivity," RSC Advances, vol. 7, no. 5, pp. 2773-2779, 2017.

[20] N. Wang, X.-K. Ouyang, L.-Y. Yang, and A. M. Omer, "Fabrication of a magnetic cellulose nanocrystal/metal-organic framework composite for removal of $\mathrm{Pb}(\mathrm{II})$ from water," 
ACS Sustainable Chemistry \& Engineering, vol. 5, no. 11, pp. 10447-10458, 2017.

[21] S. K. Elsaidi, M. A. Sinwell, A. Devaraj et al., "Extraction of rare earth elements using magnetite@MOF composites," Journal of Materials Chemistry A, vol. 6, no. 38, pp. 18438-18443, 2018.

[22] E. Wu, Y. Li, Q. Huang, Z. Yang, A. Wei, and Q. Hu, "Laccase immobilization on amino-functionalized magnetic metal organic framework for phenolic compound removal," Chemosphere, vol. 233, pp. 327-335, 2019.

[23] R. Ricco, L. Malfatti, M. Takahashi, A. J. Hill, and P. Falcaro, "Applications of magnetic metal-organic framework composites," Journal of Materials Chemistry A, vol. 1, no. 42, pp. 13033-13045, 2013.

[24] M.-X. Wu, J. Gao, F. Wang et al., "Multistimuli responsive core-shell nanoplatform constructed from $\mathrm{Fe}_{3} \mathrm{O}_{4} @ \mathrm{MOF}$ equipped with pillar[6]arene nanovalves," Small, vol. 14, no. 17, article 1704440, 2018.

[25] H. Zhang, S. Qi, X. Niu et al., "Metallic nanoparticles immobilized in magnetic metal-organic frameworks: preparation and application as highly active, magnetically isolable and reusable catalysts," Catalysis Science \& Technology, vol. 4, no. 9, pp. 3013-3024, 2014.

[26] Q. Li, S. Jiang, S. Ji, D. Shi, and H. Li, "Synthesis of magnetically recyclable MOF-5@SiO $2 @ \mathrm{Fe}_{3} \mathrm{O}_{4}$ catalysts and their catalytic performance of Friedel-Crafts alkylation," Journal of Porous Materials, vol. 22, no. 5, pp. 1205-1214, 2015.

[27] M. Zhao, X. Zhang, and C. Deng, "Rational synthesis of novel recyclable $\mathrm{Fe}_{3} \mathrm{O}_{4} @ M O F$ nanocomposites for enzymatic digestion," Chemical Communications, vol. 51, no. 38, pp. 81168119, 2015.

[28] F. Ke, L.-G. Qiu, Y.-P. Yuan, X. Jiang, and J.-F. Zhu, “ $\mathrm{Fe}_{3} \mathrm{O}_{4} @-$ MOF core-shell magnetic microspheres with a designable metal-organic framework shell," Journal of Materials Chemistry, vol. 22, no. 19, pp. 9497-9500, 2012.

[29] F. Ke, L.-G. Qiu, and J. Zhu, " $\mathrm{Fe}_{3} \mathrm{O}_{4} @ M O F$ core-shell magnetic microspheres as excellent catalysts for the Claisen-Schmidt condensation reaction," Nanoscale, vol. 6, no. 3, pp. 15961601, 2014.

[30] F. Ke, L. Wang, and J. Zhu, "Multifunctional Au-Fe ${ }_{3} \mathrm{O}_{4} @ \mathrm{MOF}$ core-shell nanocomposite catalysts with controllable reactivity and magnetic recyclability," Nanoscale, vol. 7, no. 3, pp. 12011208, 2015.

[31] Y. Chen, Z. Xiong, L. Peng et al., "Facile preparation of coreshell magnetic metal-organic framework nanoparticles for the selective capture of phosphopeptides," ACS Applied Materials \& Interfaces, vol. 7, no. 30, pp. 16338-16347, 2015.

[32] L. Huang, M. He, B. Chen, and B. Hu, "A designable magnetic MOF composite and facile coordination-based post-synthetic strategy for the enhanced removal of $\mathrm{Hg}^{2+}$ from water," Journal of Materials Chemistry A, vol. 3, no. 21, pp. 1158711595, 2015.

[33] W. Cai, S. Wu, Y. Liu, and D. Li, "A novel Prussian bluemagnetite composite synthesized by self-template method and its application in reduction of hydrogen peroxide," Applied Organometallic Chemistry, vol. 32, no. 1, article e3909, 2018.

[34] P. Tan, X.-Y. Xie, X.-Q. Liu et al., "Fabrication of magnetically responsive HKUST-1/ $/ \mathrm{Fe}_{3} \mathrm{O}_{4}$ composites by dry gel conversion for deep desulfurization and denitrogenation," Journal of Hazardous Materials, vol. 321, pp. 344-352, 2017.
[35] R. Zhao, Y. Wang, X. Li et al., "Surface activated hydrothermal carbon-coated electrospun PAN fiber membrane with enhanced adsorption properties for herbicide," ACS Sustainable Chemistry \& Engineering, vol. 4, no. 5, pp. 2584-2592, 2016.

[36] K. R. Reddy, K. Nakata, T. Ochiai, T. Murakami, D. A. Tryk, and A. Fujishima, "Facile fabrication and photocatalytic application of Ag nanoparticles- $\mathrm{TiO}_{2}$ nanofiber composites," Journal of Nanoscience and Nanotechnology, vol. 11, no. 4, pp. 3692-3695, 2011.

[37] Y. Zhou, J. Zhu, J. Yang et al., "Magnetic nanoparticles speed up mechanochemical solid phase extraction with enhanced enrichment capability for organochlorines in plants," Analytica Chimica Acta, vol. 1066, pp. 49-57, 2019.

[38] R. Zhang, Z. Wang, Z. Zhou et al., "Highly effective removal of pharmaceutical compounds from aqueous solution by magnetic Zr-based MOFs composites," Industrial \& Engineering Chemistry Research, vol. 58, no. 9, pp. 3876-3884, 2019.

[39] Y. Lu, B. Wang, Y. Yan, H. Liang, and D. Wu, "Silica protection-sacrifice functionalization of magnetic graphene with a metal-organic framework (ZIF-8) to provide a solid-phase extraction composite for recognization of phthalate easers from human plasma samples," Chromatographia, vol. 82, no. 2, pp. 625-634, 2019.

[40] H. Su, Y. Lin, Z. Wang, Y.-L. E. Wong, X. Chen, and T.-W. D. Chan, "Magnetic metal-organic framework-titanium dioxide nanocomposite as adsorbent in the magnetic solid-phase extraction of fungicides from environmental water samples," Journal of Chromatography A, vol. 1466, pp. 21-28, 2016.

[41] Q. Zhou, M. Lei, J. Li, Y. Liu, K. Zhao, and D. Zhao, "Magnetic solid phase extraction of $\mathrm{N}$ - and S-containing polycyclic aromatic hydrocarbons at ppb levels by using a zerovalent iron nanoscale material modified with a metal organic framework of type Fe@MOF-5, and their determination by HPLC," Microchimica Acta, vol. 184, no. 4, pp. 1029-1036, 2017.

[42] M. Xu, K. Chen, C. Luo, G. Song, Y. Hu, and H. Cheng, "Synthesis of $\mathrm{Fe}_{3} \mathrm{O}_{4} @ \mathrm{~m}-\mathrm{SiO}_{2} / \mathrm{PSA} @ \mathrm{Zr}-\mathrm{MOF}$ nanocomposites for bifenthrin determination in water samples," Chromatographia, vol. 80, no. 3, pp. 463-471, 2017.

[43] H. Tian, J. Peng, T. Lv, C. Sun, and H. He, "Preparation and performance study of $\mathrm{MgFe}_{2} \mathrm{O}_{4} /$ metal-organic framework composite for rapid removal of organic dyes from water," Journal of Solid State Chemistry, vol. 257, pp. 4048, 2018.

[44] R. Wo, Q.-L. Li, C. Zhu et al., "Preparation and characterization of functionalized metal-organic frameworks with core/shell magnetic particles $\left(\mathrm{Fe}_{3} \mathrm{O}_{4} @ \mathrm{SiO}_{2} @ \mathrm{MOFs}\right)$ for removal of Congo red and methylene blue from water solution," Journal of Chemical \& Engineering Data, vol. 64, no. 6, pp. 24552463, 2019.

[45] Q. Yang, S. Ren, Q. Zhao et al., "Selective separation of methyl orange from water using magnetic ZIF-67 composites," Chemical Engineering Journal, vol. 333, pp. 49-57, 2018.

[46] M. A. Karimi, H. Masrouri, H. Karami, S. Andishgar, M. A. Mirbagheri, and T. Pourshamsi, "Highly efficient removal of toxic lead ions from aqueous solutions using a new magnetic metal-organic framework nanocomposite," Journal of the Chinese Chemical Society, vol. 66, no. 10, pp. 1327-1335, 2019.

[47] L. Huang, M. He, B. Chen, and B. Hu, "Magnetic Zr-MOFs nanocomposites for rapid removal of heavy metal ions and dyes from water," Chemosphere, vol. 199, pp. 435-444, 2018. 
[48] H. Li, Q. Li, X. He et al., "The magnetic hybrid Cu(I)-MOF@$\mathrm{Fe}_{3} \mathrm{O}_{4}$ with hierarchically engineered micropores for highly efficient removal of $\mathrm{Cr}(\mathrm{VI})$ from aqueous solution," Crystal Growth \& Design, vol. 18, no. 10, pp. 6248-6256, 2018.

[49] A. A. Alqadami, M. Naushad, Z. A. Alothman, and A. A. Ghfar, "Novel metal-organic framework (MOF) based composite material for the sequestration of $\mathrm{U}(\mathrm{VI})$ and $\mathrm{Th}(\mathrm{IV})$ metal ions from aqueous environment," ACS Applied Materials \& Interfaces, vol. 9, no. 41, pp. 36026-36037, 2017.

[50] X. Min, W. Yang, Y.-F. Hui, C.-Y. Gao, S. Dang, and Z.-M. Sun, " $\mathrm{Fe}_{3} \mathrm{O}_{4} @$ @IF-8: a magnetic nanocomposite for highly efficient $\mathrm{UO}_{2}{ }^{2+}$ adsorption and selective $\mathrm{UO}_{2}{ }^{2+} / \mathrm{Ln}^{3+}$ separation," Chemical Communications, vol. 53, no. 30, pp. 4199-4202, 2017.

[51] F. Ke, J. Jiang, Y. Li, J. Liang, X. Wan, and S. Ko, "Highly selective removal of $\mathrm{Hg}^{2+}$ and $\mathrm{Pb}^{2+}$ by thiol-functionalized $\mathrm{Fe}_{3} \mathrm{O}_{4} @$ metal-organic framework core-shell magnetic microspheres," Applied Surface Science, vol. 413, pp. 266-274, 2017.

[52] F. Rouhani and A. Morsali, "Goal-directed design of metalorganic frameworks for HgII and PbII adsorption from aqueous solutions," Chemistry, vol. 24, no. 65, pp. 17170-17179, 2018.

[53] S.-W. Lv, J.-M. Liu, C.-Y. Li et al., "Fabrication of $\mathrm{Fe}_{3} \mathrm{O}_{4} @ U i O-$ 66- $\mathrm{SO}_{3} \mathrm{H}$ core-shell functional adsorbents for highly selective and efficient removal of organic dyes," New Journal of Chemistry, vol. 43, no. 20, pp. 7770-7777, 2019. 


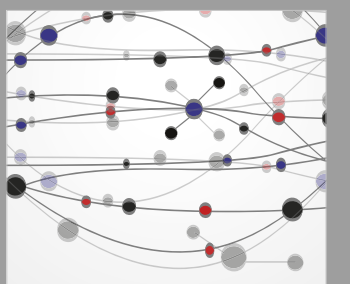

The Scientific World Journal
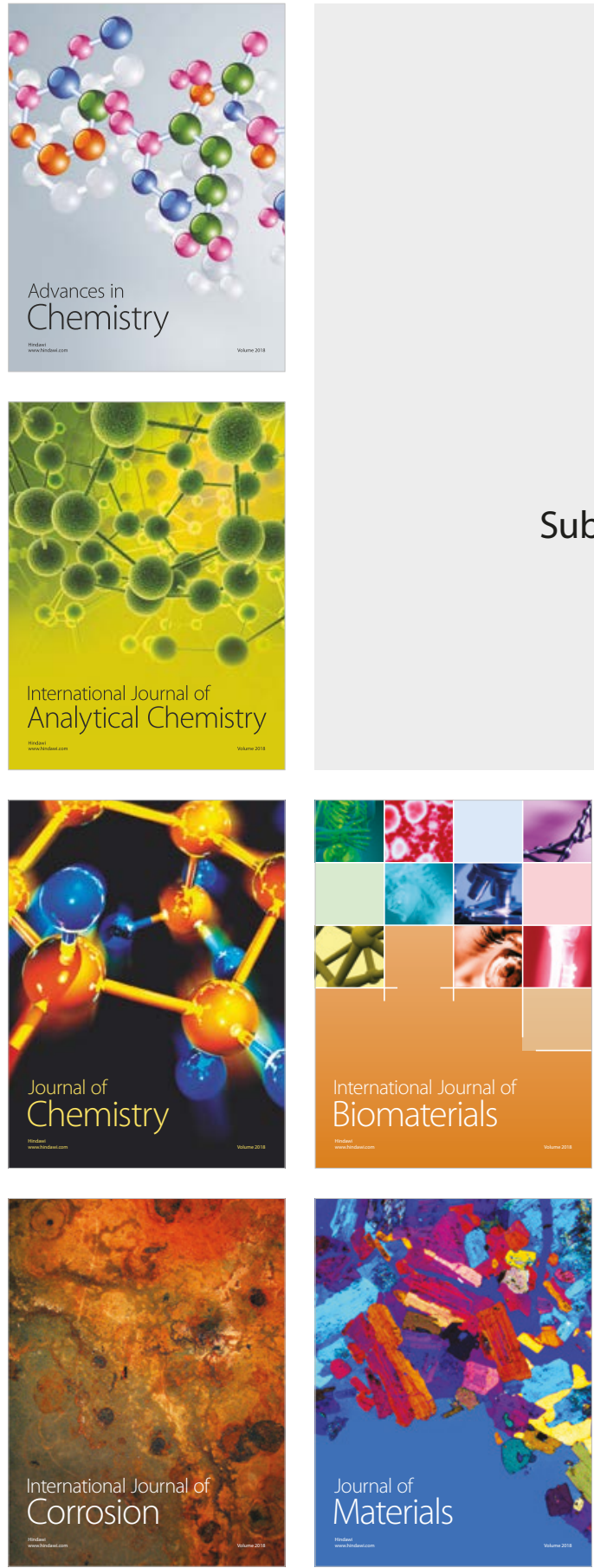

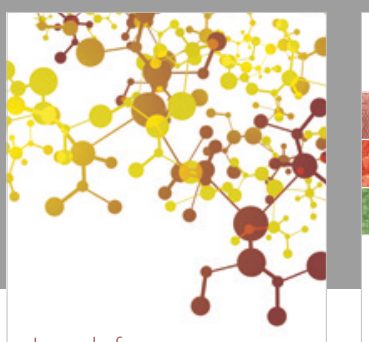

Journal of

Applied Chemistry
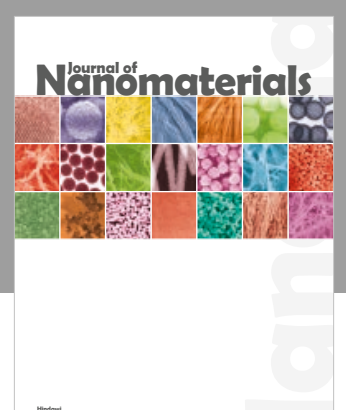

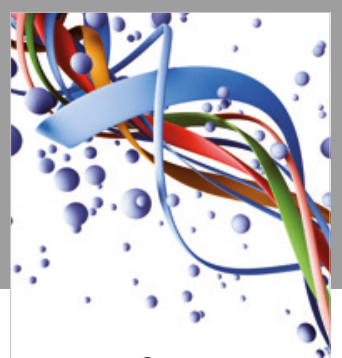

Scientifica

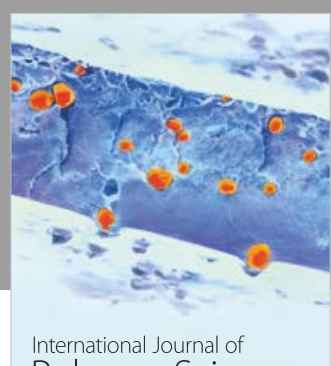

Polymer Science

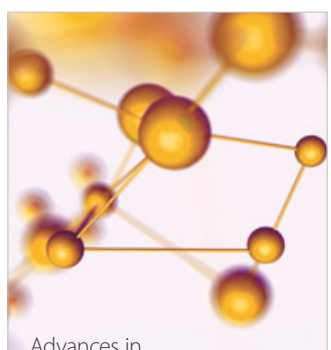

Physical Chemistry
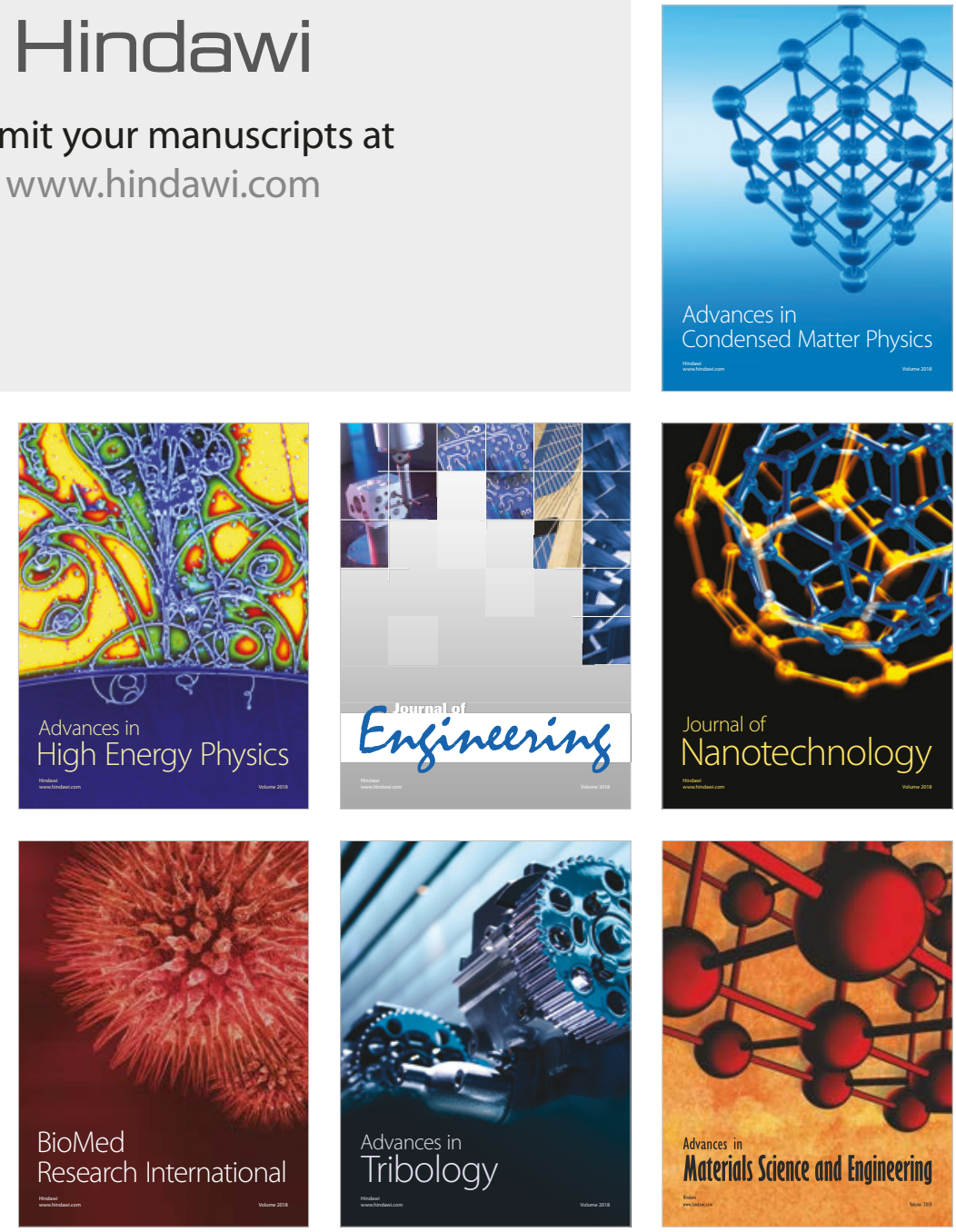